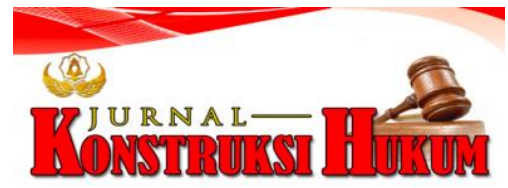

\title{
PENGELOLAAN SAMPAH PLASTIK RUMAH TANGGA, DALAM RANGKA PENCEGAHAN PENCEMARAN LINGKUNGAN (STUDY DI LINGKUNGAN KELURAHAN PEDUNGAN KECAMATAN DENPASAR SELATAN KOTA DENPASAR)
}

\author{
I Made Ode Dwiyana Putra, I Nyoman Gede Sugiartha, Luhputu Suryani \\ Fakultas Hukum Universitas Warmadewa, Denpasar-Bali, Indonesia
}

\begin{abstract}
Abstrak
Sampah plastik merupakan sampah yang tidak dapat terurai dan sangat berbahaya terhadap kondisi kesehatan lingkungan karena sampah tersebut termasuk golongan sampah non organik. Pencemaran lingkungan terjadi akibat buang sampah sembarangan. Terutama permasalahan pada pengelolaan sampah yang dihasilkan rumah tangga. Penelitian ini bertujuan untuk menganalisis kebijakan pengaturan pengelolaan sampah plastik rumah tangga sebagai upaya mencegah pencemaran lingkungan di wilayah Kelurahan Pedungan Kota Denpasar dan menjelaskan faktor yang mempengaruhi pengelolaan sampah plastik rumah tangga di Kelurahan Pedungan. Penelitian ini menggunakan penelitian hukum empiris. Pendekatan masalah yang digunakan adalah pendekatan fakta, pendekatan kasus dan pendekatan sosiologis. Data yang digunakan adalah data primer dan sekunder. Data dianalisis dan disusun secara sistematis dengan menggunakan analisa kualitatif, yaitu dengan menganalisis data yang diperoleh dari sumber data primer maupun sekunde. Hasil penelitian menunjukkan bahwa Wilayah Kelurahan Pedungan telah dikeluarkan kebijakan mengenai Surat Keputusan Kepala Kelurahan Pedungan Nomor: 660/04/I/2019 tentang Struktur Kepengurusan Bank Sampah Pedungan Asri di Kelurahan Pedungan. Bank sampah inilah yang bertugas melakukan pengelolaan terhadap sampah plastik di kelurahan pedungan. Bank sampah tersebut menerima sampah plastik untuk didaur ulang kembali menjadi barang yang lebih memiliki daya guna serta memiliki nilai ekonomis, yang kedua Faktor yang mempengaruhi pengelolaan sampah plastik di Wilayah Kelurahan Pedungan meliputi penduduk setempat dan penduduk pendatang.
\end{abstract}

Kata Kunci: Pencemaran Lingkungan; Pengelolaan sampah; Sampah Plastik; Sampah Rumah Tangga

\begin{abstract}
Plastic waste is waste that cannot be decomposed and is very dangerous to environmental health conditions because it is a non-organic waste. Prevention of environmental pollution occurs due to littering. Especially problems in the management of waste generated by households. This study aims to analyze the policy of managing household plastic waste as an effort to prevent environmental pollution in the Pedungan Village area of Denpasar City and to explain the factors that influence the management of household plastic waste in Pedungan Village. This study uses empirical legal research. The approach to the problem used is a fact approach, a case approach and a sociological approach. The data used are primary and secondary data. Data were analyzed and arranged systematically using qualitative analysis, namely by analyzing data obtained from primary and secondary data sources. The results showed that the Pedungan Urban Village area has issued a policy regarding the Decree of the Head of the Pedungan Village Number: 660/04 / I / 2019 concerning the Management Structure of the Pedungan Asri Waste Bank in Pedungan Village. This waste bank is responsible for managing plastic waste in the Pedungan village. The waste bank accepts plastic waste to be recycled back into goods that have more useful and economic value. The two factors that affect the management of plastic waste in the Pedungan Village area include local residents and immigrants.
\end{abstract}

Keywords: Environmental Pollution; Waste Management; Plastic Waste; Household Waste

\section{PENDAHULUAN}

Banyak pariwisata di Indonesia yang menjadi daya tarik bagi wisatawan asing untuk berkunjung dan bahkan menetap tinngal salah satunya pulau Bali dengan kekentalan suku yang mengkombinasikan budaya tradisional dan modern membuat banyak warga lokal dan manca negara mengunjungi pulau yang sering disebut pulau seribu pura. Kentalnya budaya yang sampai saat ini menjadi pemikat banyak mata serta banyak objek wisata yang menyajikan nuansa alam membuat Bali tidak pernah sepi dari pengunjung. Bertambahnya jumlah penduduk, sejalan dengan bertambahnya jumlah sampah yang dihasilkan. Penduduk yang datang dari luar daerah lebih banyak perbandingannya dari 
pada penduduk yang memang asli dari daerah setempat. Daerah pariwisata menjadi faktor utama dari padatnya penduduk saat ini. Daerah pariwisata di Bali menjadi daya tarik tersendiri bagi orangorang yang ingin bekerja ke daerah pariwisata. Itu sangat berpengaruh terhadap lingkungan yang tidak sesuai dengan padatnya penduduk. Sampah menjadi masalah utama dilihat dari perkembangan jumlah penduduk. Sampah yang dihasilkan sangat banyak, ini menyebabkan dampak buruk bagi lingkungan karena sampah yang dihasilkan dalam jumlah besar tidak sesuai dengan pengelolaan yang dilakukan (Suharjo, 2002). Pengaruh lingkungan adalah salah satu faktor lainnya semakin banyak pergaulan interaksi timbal balik antara individu satu dengan individu lainnya atau individu dengan kelompok membuat semakin cerdas pemikiran seseorang (Mujahidah, 2015).

Seiring perkembangan zaman di Propinsi Bali semakin banyak bangunan yang mewah terutama dari bagia sektor pariwisata. Tidak semua pembangunan membawa dampak positif bagi masyarakat tetapi membawa dampak negatif seperti dengan banyaknya wisatawan dengan berbagai gaya berdandan dan berpakaian membuat masyarakat mengikuti gaya glamor yang diperlihatkan wisatawan dan juga banyaknya wisatawan yang tidak memperdulikan kebersihan lingkungan membuat banyak sampah makanan, minuman serta sisa dari kegiatan yang dilakukan wisatawan membuat kini keadaan Indonesia khususnya Bali menjadi tercemar. Tempat wisata bagaikan tempat sampah, sampah plasatik yang merupakan bahan yang paling lama punah ada dimana-mana dan jeleknya lagi banyak masyarakat yang tidak memperdulikannya dan bahkan semakin mengotori dengan mengikuti gaya wisatawan membuang sampah sembarangan. Semakin hari meningkat tingkat pencemara lingkungan, kini sampah plastik menggunung di pesisir pantai yang terbawa ombak dapat dikatakan akibat dari pada wisatawan yang datang ke Indonesia membuat kita menjadi salah satu penyumbang sampah terbanyak di dunia. Keadaan ini pula yang membuat pekerja kebersihan kewalahan membersihkan sampah yang tiap hari semakin menumpuk.

Efek pemumpukan sampah yang semakin bertambah setiap harinya membuat keadaan semakin parah, tercemarnya air, panasnya suhu yang akhir-akhir ini terjadi diakibatkan banyak tumbuhan yang ditebangi dan pada saat hujan banyak jalanan menjadi banjir yang tidak sedikit memakan korban harta benda warga yang hanyut terbawa air.

Sebagai manusia yang yang hidupnya tidak terlepas dari alam sebaiknya mengerti tentang kondisi saat ini sudah seharusnya sadar diri sedini mungkin tentang betapa pentingnya melestarikan lingkungan bukan mengikuti kebiasaan wisatawan yang mengotori lingkungan sekitar tanpa memikirkan efek perbuatannya tersebut (Taufiq, 2014). Sebuah kesalahan besar bila masyarakat lokal asli Indoensia tidak memperdulikan lingkungan harusnya dimulai dari diri sendiri membuang sampah pada tempatnya, memperingatkan jika melihat seseorang yang membuang sampah sembarangan dan masih banyak upaya yang dapat dilakukan demi menjaga keasrian lingkungan sekitar.

Pembangunan boleh dilakukan besar-besaran tetapi jangan melupakan melestarikan lingkungan jangan membiarkan wisatawan mengotori lingkungan dengan alasan apapun. Semua harus dilakukan demi mengembalikan wajah Indonesia yang asri, bersih, rapi, indah tanpa polusi yang dapat menggnggu kesehatan makhkuk hidup. Pemerintah menilai bahwa banyak orang yang tidak peduli alam adalah kesalahan fatal dengan demikian dibuatkanlah peraturan dari pemerintah tentang larangan membuang sampah sembarangan. Tujuan diberakukannya peraturan tersebut agar lingkungan kembali menjadi bersih serta menjadi pembelaran yang dengan sengaja atau tidak sengaja membuang sampah dan mengotori lingkungan. Bersama-sama menghijaukan kembali lingkungan adalah hal yang mudah namun tidak ada respon atau tindakan dari masyarakat membuat upaya pemerintah mejadi sulit untuk direalisasikan. Sia-sia peraturan yang telah menjelaskan secara detail mengenai lingkungan dan sanksi bagi seseorang yang mengotori lingkungan kalau warganya saja tidak perduli kenapa wisatawan juga harus peduli.

Penellitian terdahulu mengungkapkan bahwa Pengelolaan sampah rumah tangga bisa dilakukan dengan baik dan menjadi solusi alternative untuk membantu pemerintah melakukan penanganan terhadap sampah (Hayat \& Zayadi, 2018). Menurut Riswan et al., (2011) Dalam pengelolaan sampah harusnya dibuat penegakkan hukum/peraturan daerah yang tegas, serta melibatkan pihak swasta dan masyarakat dalam aspek pembiayaannya sehingga semua elemen masyarakat lokal berperan dalam penjagaan pencemaran lingkungan. Penegakan hukum dalam pengelolaan sampah mengacu pada tiga sistem hukum yang merupakan gabungan dari komponenkomponen yaitu struktur, substansi dan budaya (Candrakirana, 2015). Diketahui dari beberapa 
peneletian tedahulu bahwa permasalahan sampah di Indonesia merupakan permasalahn lingkungan yang serius yang masih terus berkembang oleh sebab itu Penelitian ini bertujuan untuk menganalisis kebijakan pengaturan pengelolaan sampah plastik rumah tangga sebagai upaya mencegah pencemaran lingkungan di wilayah Kelurahan Pedungan Kota Denpasar dan menjelaskan faktor yang mempengaruhi pengelolaan sampah plastik rumah tangga di Kelurahan Pedungan.

\section{METODE PENELITIAN}

Penelitian ini menggunakan penelitian hukum empiris. Pendekatan masalah yang digunakan adalah pendekatan fakta, pendekatan kasus dan pendekatan sosiologis. Data yang digunakan adalah data primer dan sekunder. Data dianalisis dan disusun secara sistematis dengan menggunakan analisa kualitatif, yaitu dengan menganalisis data yang diperoleh dari sumber data primer maupun sekunder (Waluyo, 1996). Data primer didapatkan melalui wawancara langsung kepada ibu rumah tangga, karena mereka yang lebih banyak berperan dalam mengurus kegiatan rumah tangga termasuk dalam hal pengelolaan sampahnya, sedangkan data sekunder diperoleh melalui sumber hukum lain yang berkaitan dengan kebijakkan dalam pengelolaan sampah

\section{HASIL DAN PEMBAHASAN}

\section{Pengaturan Pengelolaan Sampah Plastik Rumah Tangga Sebagai Upaya Mencegah Pencemaran Lingkungan di Wilayah Kelurahan Pedungan Kota Denpasar}

Bali menjadi salah satu provinsi di Indonesia yang memiliki banyak objek wisata yang dikagumi wisatawan asing sehingga tiap tahunnya jumlah wisatawan terus meningkat. Daerah pusat perekonomian menjadi salah satu faktor meningkatnya jumlah penduduk yang sejalan dengan peningkatan jumlah penghasil sampah setiap harinya. Hal tersebut berpengaruh terhadap kondisi lingkungan yang semakin menurun. Pentingnya dan sangat diperlukannya edukasi tentang pengelolaan serta pengolahan sampah khususnya sampah plastik (Asteria \& Heruman, 2016). Tempat dimana kekhasan budaya yang berlandaskan ajaran Tri Hita Karanayang berarti bahwa dalam kehidupan harus terdapat keseimbangan antara pencipta, manusia dan juga alam lingkungannya.

Implementasi dari asas tersebut yaitu mengamanatkan terwujudnya rasa aman, tenteram, tertib dan nyaman dalam menjalani aktivitas kehidupan sehari-hari. Untuk mewujudkan hal tersebut terdapat salah satu persoalan yang dihadapi yang bersifat urgent sampai saat ini di Provinsi Bali, khususnya di Kota Denpasar yaitu permasalahan terkait sampah yang menyebabkan terganggunya ketertibanumum menyebabkan wabah penyakit dan pencemaran lingkungan di Kota Denpasar akibat tumpukan-tumpukan sampah yang tidak dikelola dengan baik. Semakin lama, tindakan oleh umat manusia ini semakin tidak terkendali yang menyebabkan terjadinya dampak negatif akibat dari kerusakan lingkungan seperti banjir dan terutama terjadinya penumpukan sampah yang hampir merata di setiap wilayah yang sangat mengkhawatirkan (Basriyananta, 2007).

Pencemaran lingkungan merupakan hal utama yang terjadi dalam daerah tinggi pariwisata dan sebagai pusat perekonomian. Daerah tersebut seperti Kota Denpasar yang menjadi pusat pariwisata dan pusat perekonomian. Masalah yang tidak bisa hanya diselesaikan satu pihak saja tetapi kebersamaan, keadaan yang boleh dianggap enteng karena menyangkut masa depan generasi berikutnya, apa bila sebagai generasi sekarang tidak memperdulikan lingkungan maka yang akan menanggung perbuatan adalah generasi berikutnya. Sebagai warga yang tidak ingin masa depan menjadi buruk sedini mungkin memberlakukan hidup sehat, mengurangi pemakaian kantong plastik, berhenti membakar sampah, tidak membuang sampah sembarangan, maka dapat dipastikan masa depan akan dipenuhi oleh oksigen baik, kebersihan air, kesuburan tanah dan banyak pepohonan rimbun.

Pemerintah memperingatkan para distributor kendaraan agar mengurangi emisi gas buang yang menimbulkan polusi dimana-mana jika kedepan tidak ada lagi polusi dapat dibayangkan betapa segarnya udara setiap hari dan membuat masyarakat menjadi semakin sehat. Berdasrkan hal ini dikeluarkan kebijakan mengenai Surat Keputusan Kepala Kelurahan Pedungan Nomor: 660/04/I/2019 tentang Struktur Kepengurusan Bank Sampah Pedungan Asri di Kelurahan Pedungan. Bank sampah inilah yang bertugas melakukan pengelolaan terhadap sampah plastik di kelurahan pedungan. Bank sampah tersebut menerima sampah plastik untuk didaur ulang kembali menjadi barang yang lebih memiliki daya guna serta memiliki nilai ekonomis 


\section{Faktor Yang Mempengaruhi Pengelolaan Sampah Plastik Rumah Tangga di Kelurahan Pedungan.}

Pencemaran lingkungan tidak lepas kaitannya dengan lingkungan hidup. Pencemaran lingkungan yang disebabkan oleh beberapa faktor. Faktor utama penyebab pencemaran lingkungan adalah sampah sampah dihasilkan oleh kegiatan manusia yang dapat berpengaruh buruk terhadap kondisi lingkungan hidup. Kemajuan manusia yang ditandai dengan semakin berkembangnya ilmu pengetahuan dan teknologi, manusia semakin leluasa memanfaatkan sumber daya alam dan lingkungan hidup (Salim, 1979). Tetapi tidak sejalan dengan pemeliharaan yang dilakukan. Sebagai contoh dalam mencemari lingkungan yang dilakukan oleh kegiatan manusia sehari-harinya. Tidak bisa dipungkiri bahwa padatnya penduduk membuat sampah menjadi meningkat karena setiap orang setiap harinya minimal satu saja kantong plastik dikali banyaknya jumlah masyarakat maka akan terjadi penumpukan sampah, bertambahnya sampah yang di hasilkan aktivitas manusia membuat para petugas kebersihan menjadi kewalahan disamping kurangnya tenaga juga kurangnya alat yang dapat mendaur ulang sampah plastic.

Pencegahan pencemaran lingkungan terdiri dari langkah pencegahan dan pengendalian. Langkah pencegahan pada prinsipnya mengurangi pencemar dari sumbernya untuk mencegah dampak lingkungan yang lebih berat. Di lingkungan yang terdekat, misalnya dengan mengurangi jumlah sampah yang dihasilkan, menggunakan kembali (reuse), mengurangi (reduce), dan daur ulang (recycle). Kemajuan industri dan teknologi ternyata telah menambah berbagai jenis sampah yang ditimbulkan oleh aktivitas rumah tangga. Pencemaran daratan umumnya berasal dari limbah rumah tangga yang berbentuk padat yang dikumpulkan disuatu tempat pembuangan akhir (TPA). Untuk menunjang kehidupan manusia sebagian tempat dialokasikan menjadi TPA, akan tetapi walaupun sudah disediakan TPA, kuantitas volume sampah yang dihasilkan oleh limbah rumah tangga semakin melebihi kapasitas yang ada karena meningkatnya volume sampah yang signifikan tiap tahunnya, sehingga kerap timbul bencana alam akibat permasalahan sampah tersebut. Pemanfaatan kembali sampah rumah tangga dilakukan untuk memberikan keuntungan bagi kehidupan manusia. Sampah rumah tangga yang awalnya tidak bermanfaat dapat menjadi bahan yang bermanfaat. Sampah organik biasanya berupa limbah rumah tangga yang dapat membusuk atau terdegradasi oleh mikro organisme. Oleh karen bahan buangan organik dapat membusuk atau terdegradasi maka akan sangat bijaksanan apabila bahan buangan yang termasuk kelompok ini tidak dibuang ke air lingkungan karena akan dapat menaikkan populasi mikroorganisme di dalam air. Dengan bertambahnya populasi mikroorganisme di dalam air maka tidak menutup kemungkinan berkembangnya bakteri potagen yang berbahaya bagi manusia. Sampah organik sebaiknya dikumpulkan untuk diproses menjadi pupuk buatan (kompos) yang berguna bagi tanaman. Pembuatan kompos ini berarti mendaur ulang sampah organik yang tentunnya berdampak positif bagi lingkungan hidup manusia (Hamzah, 1995).

Masyarakat Bali dan pemerintah setempat dapat bekerja sama menggulangi sampah plastik yang semakin hari tidak ada habisnya dengan membiasakan hidup bersih dan tidak mengabaikan sampah yang ada disekitar lingkungan. Salah satu cara mengantisipasi penumpukan limbah rumah tangga atau limbah pabrik yang bahkan kita sendiri tidak bisa menghentikan penggunaannya adalah membuat lubang biopori dengan media botol plastik yang di tanam didalam tanah akan membuat tanah menjadi subur bahkan bisa dibuat menjadi pupuk dengan jangka waktu tertentu.

\section{SIMPULAN DAN SARAN}

\section{Simpulan}

Berdasarkan hasil analisis data dapat disimpulkn bahwa Provinsi Bali di Wilayah Kota Denpasar khususnya di Wilayah Kelurahan Pedungan sudah diterapkan kebijakan tentang pengelolaan sampah plastik rumah tangga yang mencegah pencemaran lingkungan dengan dikeluarkan kebijakan mengenai Surat Keputusan Kepala Kelurahan Pedungan Nomor: 660/04/I/2019 tentang Struktur Kepengurusan Bank Sampah Pedungan Asri di Kelurahan Pedungan. Bank sampah inilah yang bertugas melakukan pengelolaan terhadap sampah plastik di kelurahan pedungan. Bank sampah tersebut menerima sampah plastik untuk didaur ulang kembali menjadi barang yang lebih memiliki daya guna serta memiliki nilai ekonomis, yang kedua Faktor yang mempengaruhi pengelolaan sampah plastik di Wilayah Kelurahan Pedungan meliputi penduduk setempat dan penduduk pendatang yang masih memiliki tinghat kesadara rendah akan kebersihan lingkungan. 


\section{Saran}

Adapun yang menjadi saran adalah kepada pemerintah kelurahan perlu soisalisasi yang terus menerus pada masyarakat tentang kebijakan kelurahan tersebut, karena masyarakatnya masih kurang memahami terhadap kebijakan yang dikeluarkan oleh Kelurahan Pedungan mengenai pengelolaan sampah plastik. Kesadaran pengelolaan sampah plastik yang berawal dari rumah tangga kurang dapat dikelola dengan baik sebelum diambil oleh petugas kebersihan, yang kedua tempat-tempat usaha yang dimiliki individu sebaiknya dibatasi penggunaan plastik sekali pakai. Selain usaha individu, pasar juga perlu dibatasi penggunaan sampah plastiknya. Hal ini sangat berpengaruh signifikan terhadap pengelolaan sampah agar tidak terjadi kelebihan kapasitas dalam penampungan sampah.

\section{DAFTAR PUSTAKA}

Asteria, D., \& Heruman, H. (2016). Bank Sampah Sebagai Alternatif Strategi Pengelolaan Sampah Berbasis Masyarakat di Tasikmalaya. Jurnal Manusia Dan Lingkungan, 23(1), 136-141.

Basriyananta. (2007). Memanen Sampah. Kanisius.

Candrakirana, R. (2015). Penegakan Hukum Lingkungan dalam Bidang Pengelolaan Sampah Sebagai Perwujudan Prinsip Good Environmental Governance di Kota Surakarta. Yustisia Jurnal Hukum, 4(3), 581-601.

Hamzah. (1995). Penegakan Hukum Lingkungan. Arikha Media Cipta.

Hayat, \& Zayadi, H. (2018). Model Inovasi Pengelolaan Sampah Rumah Tangga. Jurnal Ketahanan Pangan, 2(2), 131-141.

Mujahidah. (2015). Implementasi Teori Ekologi Bronfenbrenner dalam Membangun Pendidikan Karakter yang Berkualitas. Lentera, 19(2), 171-185.

Riswan, Sunoko, H. R., \& Hadiyarto, A. (2011). Pengelolaan Sampah Rumah Tangga di Kecamatan Daha Selatan. Jurnal Ilmu Lingkungan, 9(1), 31-39.

Salim, E. (1979). Lingkungan Hidup dan Pembangunan. Mutiara Sumber Widya.

Suharjo. (2002). Kondisi Pengelolaan Sampah dan Pengaruh Terhadap Kesehatan Masyarakat di Dki Jakarta. In Media Litbang Kesehatan (Vol. 12, Issue 4, pp. 37-42).

Taufiq, A. (2014). Upaya Pemeliharaan Lingkungan oleh Masyarakat di Kampung Sukadaya Kabupaten Subang. Jurnal Gea, 14(2), 124-134.

Waluyo, B. (1996). Penelitian Hukum Praktek. Sinar Grafika. 